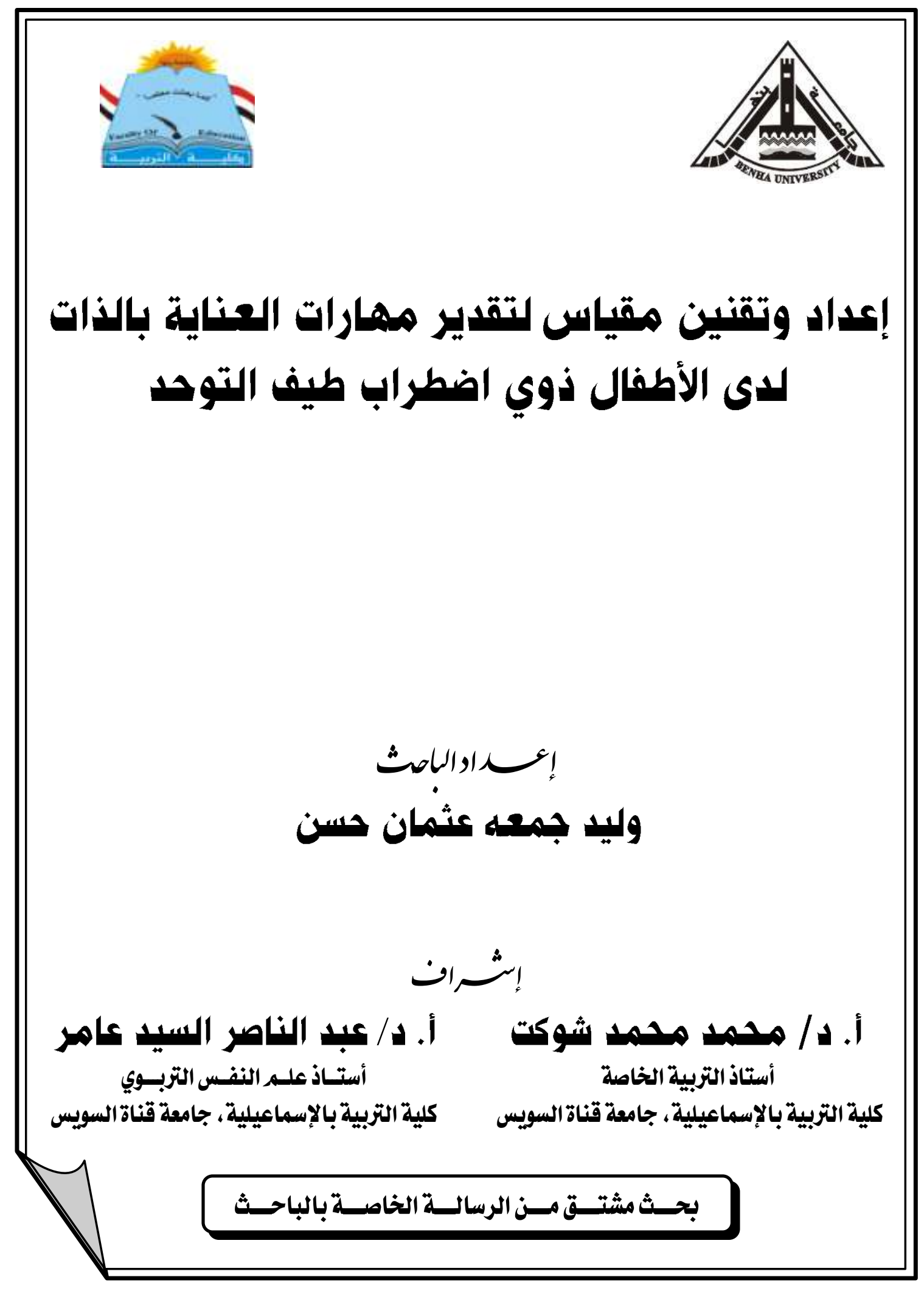




\section{إعداد وتقنين مقياس لتقدير مهارات العناية بالذات \\ لدى الأطفال ذوي اضطراب طيف التوح}

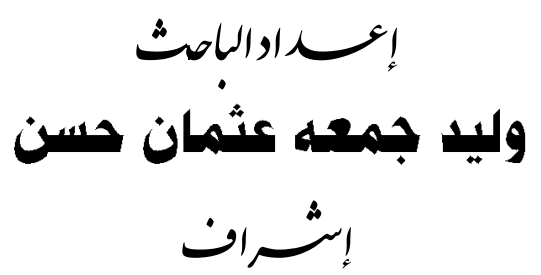

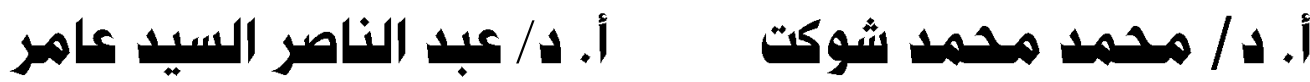

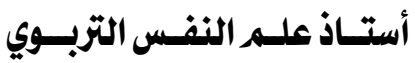

أستاذ التربية الخاصة

كلية التربية بالإسماعيلية، جامعة قناة السويس كلية التربية بالإسماعيلية، جامعة قناة السويس

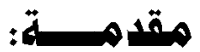

تعد السنوات الأولى في حباة الطفل ذي اضطراب طبف الثوحد من أهم مراحل نموه حيث أنها السنوات التي يثم فيها ثشكيل شخصيثه الإنسانية ووضع اللبنات الأولى لبنائها، ورلا تعود نتائج الاهنمام بالأطفال ذوي اضطر اب طيف التوحد في هذه المرحلة إليهم فحسب بل تعود على المجنمع ككل على المدى البعبد. وثأثي خدمات النذخل المبكر والني تعد ثربية مبكرة من نوع خاص لتهثم برعاية وتأهيل الأطفال ذوي اضطراب طيف التوحد وأسرهم، وذلك منذ وبن اكتشاف الاضطر اب مباتشرة.

ويعد الطبيب النفسي ليوكانر Leo kanner أول من عرف اضطر اب طيف الثوحد من خلال ملاحظته لإحدى عشرة حالة هن الأطفال المتخلفين عقلياً بجامعة هارفارد في الولايات المتحدة الأمريكية حبث وصف السلوكيات و الخصائص المميزة لاضطراب طيف الثوحد والثي هي لهي

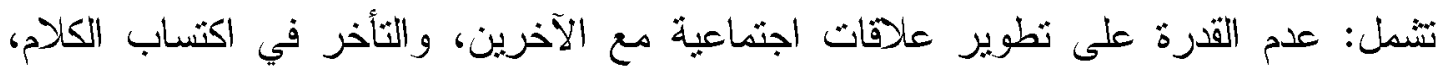
و استعمال غير نواصلي للكلام بعد تطوره، ونشاطات لعب نمطية ونكرارية، و المحافظة على

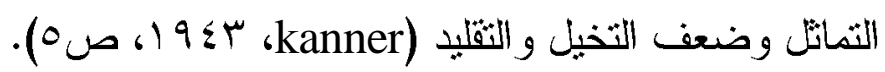

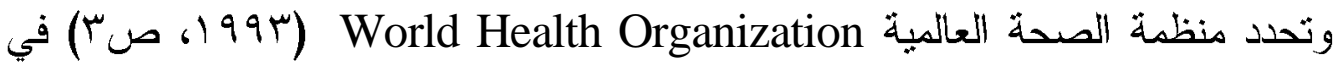
التصنيف الدولي العاثر للأمراض ICD-10 اضطر اب طيف التوحد بأنه "اضطراب نمائي منتشر يؤثر سلباً على عدة مجالات لعلية التطور، ويتسم بوجود نمو غير طبيعي أو مختل أو كليهما يصبب الطفل قبل أن يبلغ الثالثة من عمره، كما بتسم أيضاً بوجود نوع من الأداء غير بردير 
السوي في ثلاثة مجالات هي: التفاعل الاجنماعي، والتواصل اللفظي وغير اللفظي، والسلوك النمطي المقيد النكراري".

ولقد استهذف العلماء و الباحثون منذ بداية الاهنمام بالأطفال ذوي اضطر اب طيف التوحد

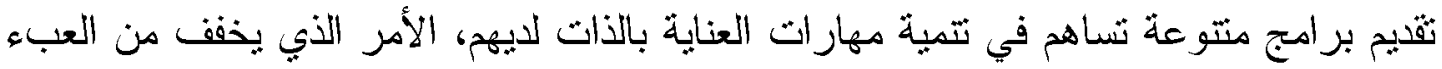

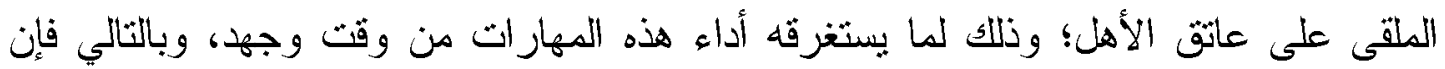

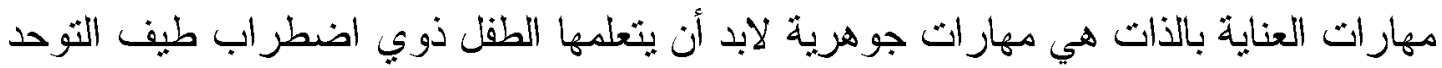

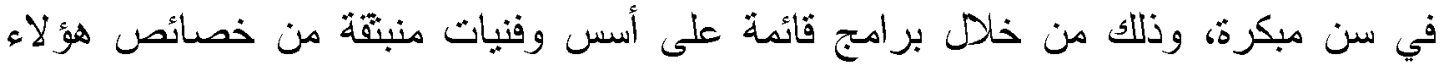

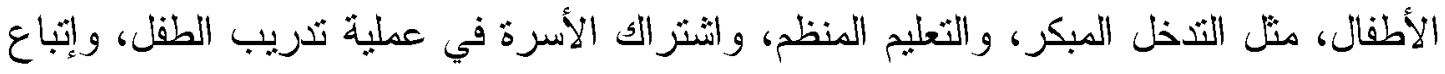
نظريات تعديل السلوك وغيرها. وفي هذا الإطار يهدف البحث الحالي إلى مساعدة الأسرة

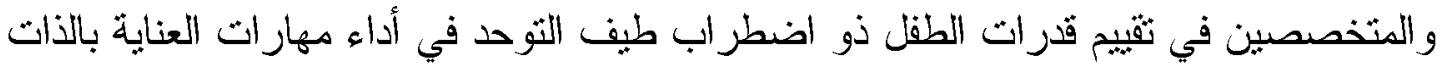

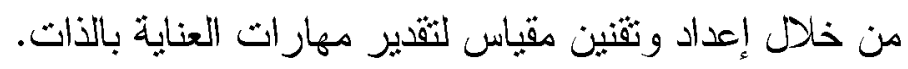

أولاً: مشكاسة البحـثـ:-

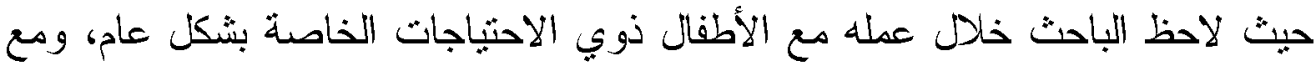

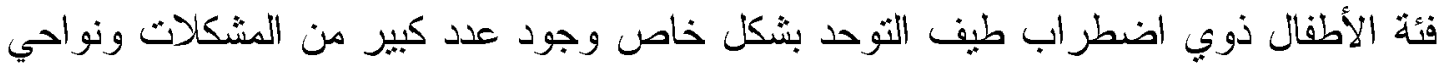

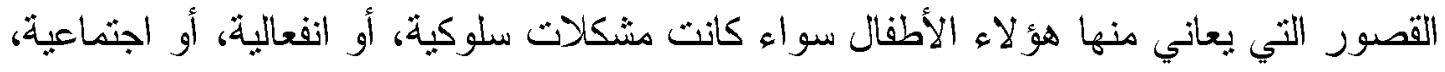
ومن بينها عجز الطفل ذوب اضطراب طيف التوحد عن أداء مهارات العناية بالذات منل:

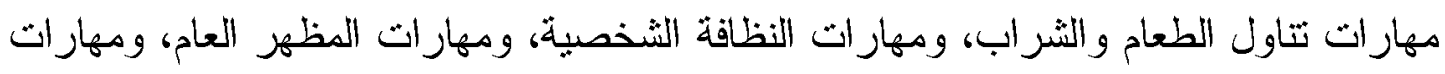

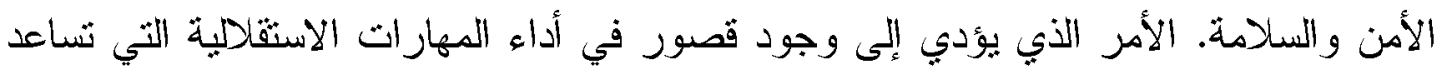

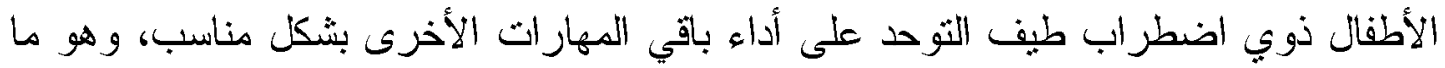

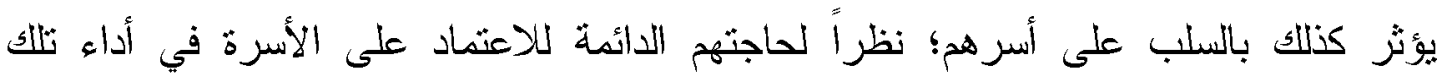

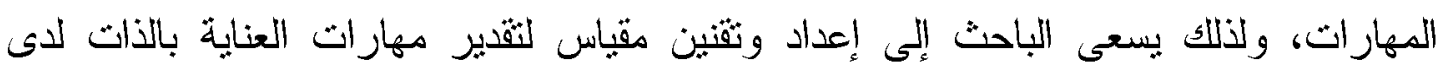

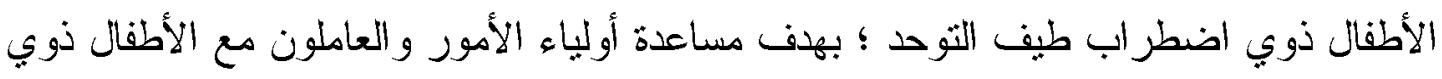
اضطراب طبف التوحد في تقدير هدى قدرة الطفل على أداء هذه المهارات حتى يتم تثيبمه وتنريبه بنكل ملائم. ومن هنا يمكن أن تتحدد مثكلة الار اسة في الثالي: إعداد وتقنين مقياس لتقاير مهارات العناية بالأات لاى الأطفال ذوى اضطراب طيف 


$$
\begin{aligned}
& \text { ويتثرع من هذه الهدف الرئيسي الأهداف الثالية: }
\end{aligned}
$$

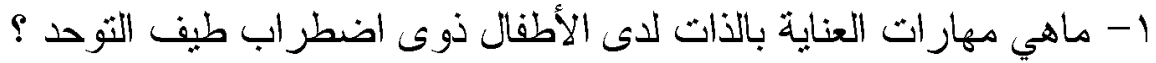

$$
\begin{aligned}
& \text { Y- ما هي ابعاد مهارات العناية بالذات لدى الأطفال ذوى اضطر اب طيف الآن التوحد ؟ }
\end{aligned}
$$

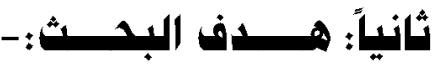

يهدف البحث الحالي إلى إعداد وتقتين مقياس التقدير مهارات العناية بالذات لدى الأطفال

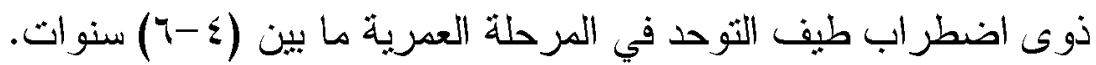

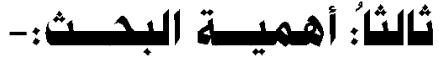

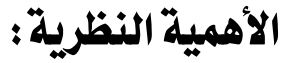

1- يتتاول البحث جانباً هاماً وظاهرة واضحة لدى الأطفال ذوبي اضطراب طيف التوحد

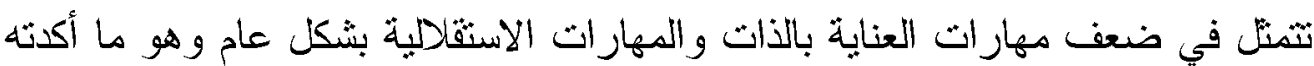

$$
\text { العديد من الدراسات السابقة. }
$$

r- يقدم هذه البحث إطاراً نظرياً قد بستفبد منه العاملون بحقل ذوي الاحتباجات الخاصة عامة، و المهتمون باضطر اب طيف التوحد بصفة خاصة.

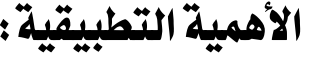

1- مساعدة أسر الأطفال ذوبي اضطراب طيف التوحد من خلا المساهمة في توفير مقاييس تدريييه يمكنه تطيقها في المنزل لنقفير مهارات العناية بالذات لدى الطقل ذي

$$
\text { اضطر اب طيف التوحد. }
$$

Y- إعداد مقياس تقير مهارات العناية بالذات للأطفال ذوي اضطر اب طيف التوحد.

\section{رابعا: مصطلحسـات البحـث:-}

\section{الأطفال ذوو اضطراب طيف التوحل Children with autism spectrum disorder}

يقصد الباحث بالأطفال ذوي اضطراب طيف التوحد "الأطفال الذين نم نشخيصهم ضمن اضطر اب طيف التوحد بواسطة (الطبيب النفسي أو الأخصائي النفسي أو أخصائي التخاطب)، وينطبق عليهز مقياس جيليام التقير اضطراب التوحد (إعداد: جيليام جيمس، ونزجمة وتثنين:

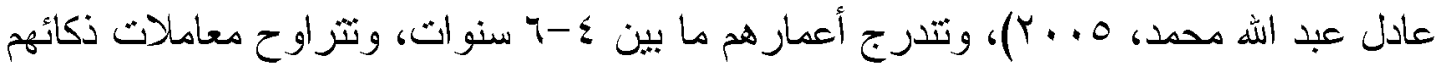
ما بين 00- • V درجة على مقياس ستانفورد بينيه الصورة الخامسة". 


\section{مهارات العناية بالذات Self-care Skills}

يقصد الباحث بمهارات العناية بالذات " تلاك المهارات التي تشتنمل على؛ مهارات تتاول الطعام والثراب، ومهارات النظافة الثخصية، وههارات المظهر العام، وههارات الأمن و السلامة، وذلك كما ثُقاس بمقياس ثقدير مهار ات العناية بالذات إعداد الباحث الحالي".

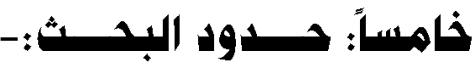

$$
\begin{aligned}
& \text { بتحدد البحث الحالي في: }
\end{aligned}
$$

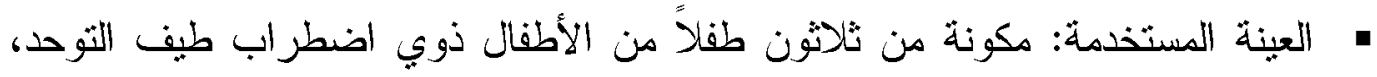

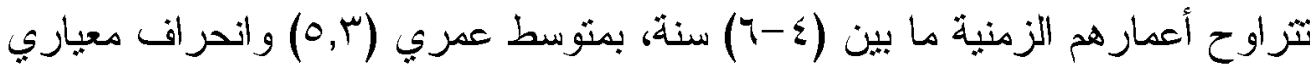
.$(\cdot, 0 \Sigma)$ • الحدود المكانية: عدد من مراكز ثأهيل الأطفال ذوب الاحتباجات الخاصة بمحافظة الثرقية وهي: (أكاديمية الحنان للنخاطب ونتمية المهارات- مركز بكرة أحلى للتخاطب التبل وتتمية المهارات - مركز الحباة للتربية الخاصة).

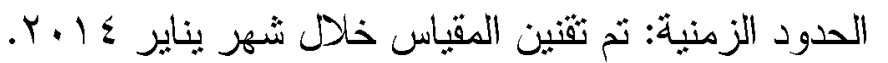

\section{الإطار النظري والدراسات السابقة:}

أولاً: مفهوم اضطراب طيف التوح:-

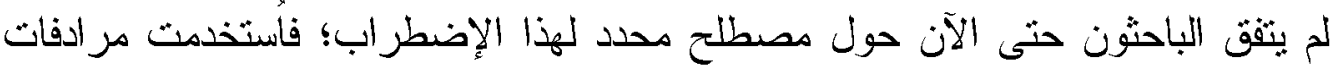

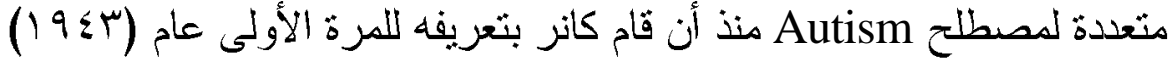
و الباحث يفضل استخدام مصطلح اضطر اب طيف التوحد للأسباب الآتية: 1 - أنه يثبير إلى أحد الخصائص الرئيسية لدى الطفل ذوي اضطر اب طيف الثوحد، وهي قصور

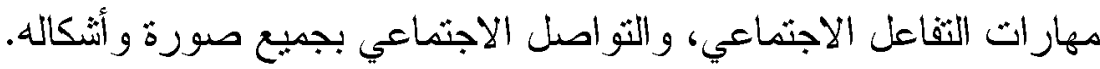

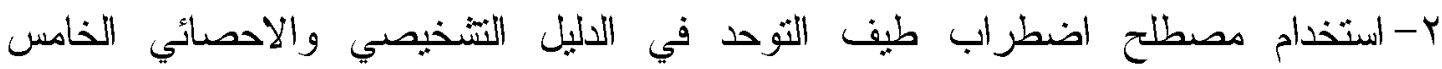

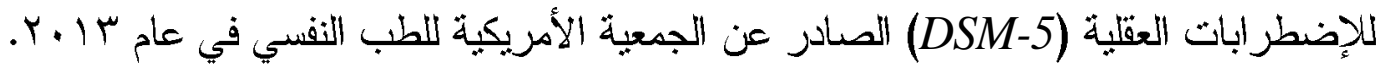

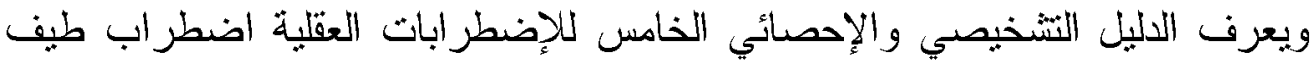

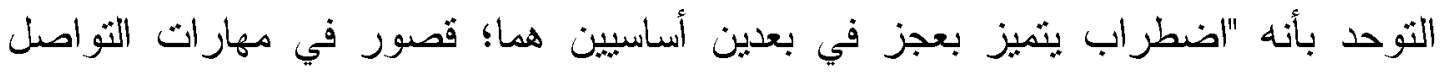
الاجتماعي والتفاعل الاجنماعي، ووجود سلوكيات نمطية نكرارية، ومحدودية النشاطات

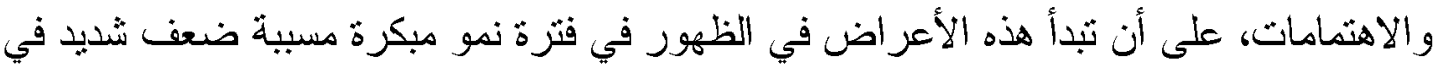

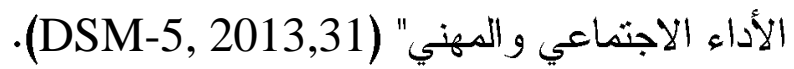




\section{ثانياً: خصائص الأطفال ذوو اضطراب طيف التوحد:-}

بنصف الأطفال ذوي اضطراب طيف التوحد بمجموعة من الخصائص والتي تثمنل فيما يلي:

$$
\begin{aligned}
& \text { • ضعف التفاعل الاجتماعي. } \\
& \text { • القصور اللغوي. } \\
& \text { • السلوك النمطي المتصف بالتكرار . } \\
& \text { • عدم القدرة على اللعب التخبلي. } \\
& \text { • يكون اضطر اب طيف التوحد قبل سن الثالثة. } \\
& \text { • نوبات الغضب وإيذاء الذات. }
\end{aligned}
$$

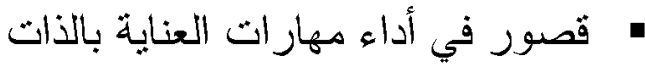

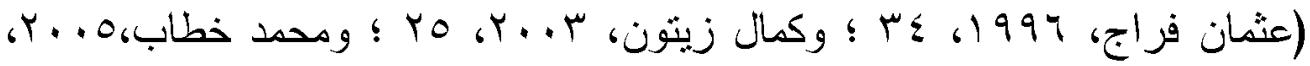

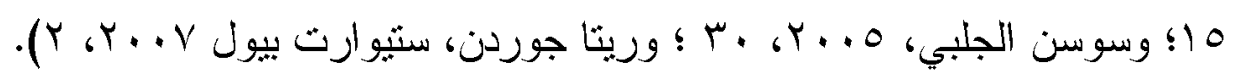

\section{ثالثاً: نسبة انتشار اضطراب طيف التوح:-}

تعددت الدراسات التي ذكرت نسبة ومدى شيوع اضطراب طيف التوحد حيث أثنار

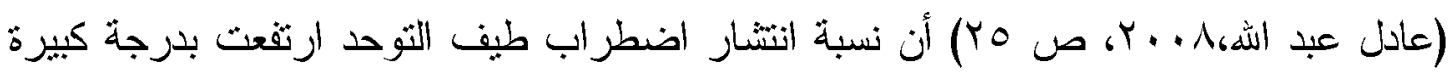

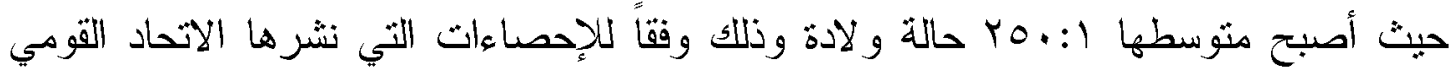
لاراسات وبحوث اضطراب طيف الثوحد بالولايات المتحدة الأمريكية. أما عن نسبة انتئار

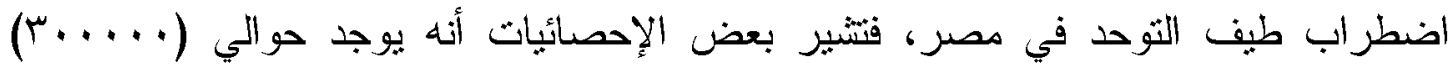

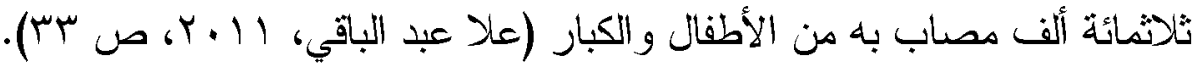

\section{رابعا: مفهوم مهارات العناية بالذات:-}

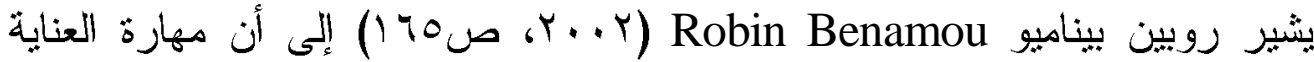
بالذات لاى الأطفال غير العاديين من المهارات الني ثهدف إلى تنمية القدرة على التكيف الناجح

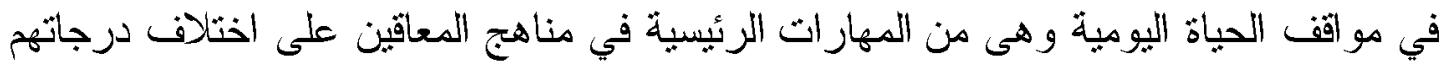

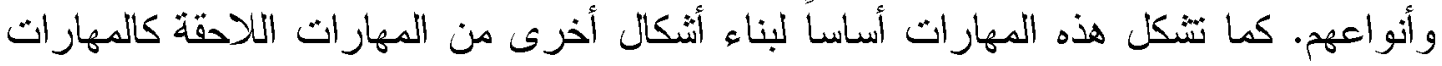

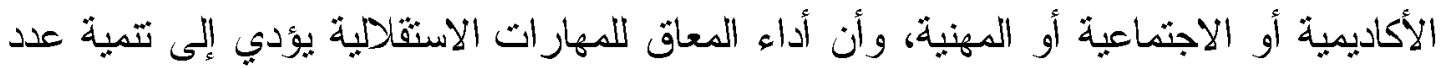

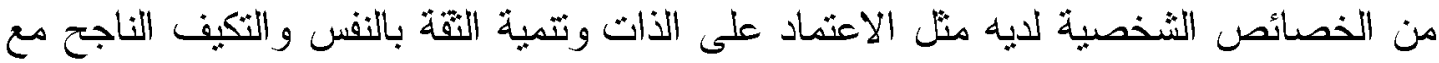

$$
\text { من حوله. }
$$

\section{r19}


ويعرف جيمس وتيكن وكيركال James, Tekin \& Kircaali (9. J (90،

مهارات العناية بالذات بأنها "المهارات العملية الثي تمكن الطفل أو البالغ من أن بعيش حياة أكثر

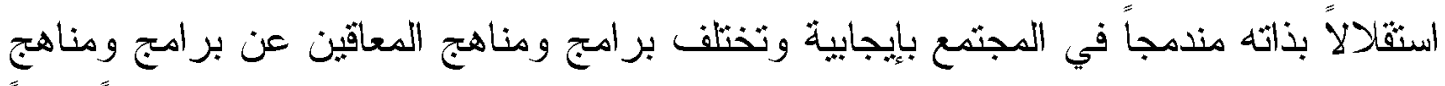

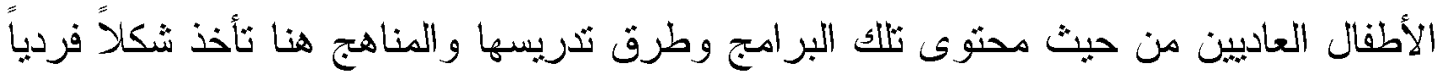

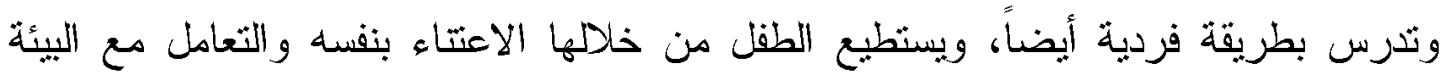
الدحيطة به، وفى النهاية يستطيع الطقل الاندماج مع المجنمع".

\section{خامساً: أهمينة مهارات العناية بالذات:-}

تعتبر مهارات العناية بالذات من أهم الأمور التي يجب على الألى الأم الاهتمام بها ونعليمها

$$
\text { لطفلها؛ لأنها تتعلق بعدة جو انب منها: }
$$

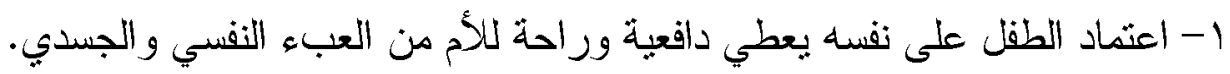

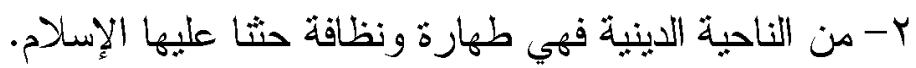

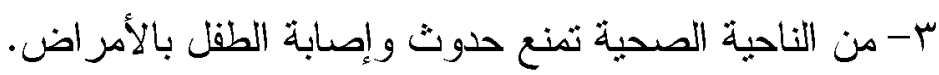
ـ - من الناحية التعليمية تساعد الطفل في جميع المجالات. ه- من الناحية الاجتماعبة تجعل الطقل مقبو لاًا من الناس.

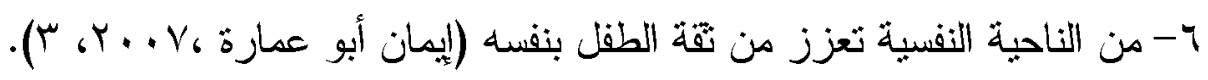

سادسا: مجالات مهارات العناية بالذات:-

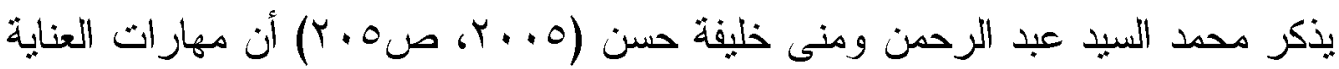
بالذات التي بمكن تعليمها للأطفال ذوي اضطر اب طيف التوحد نتشنمل على المجالات الثالية:

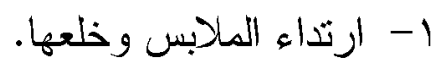

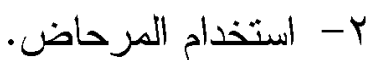

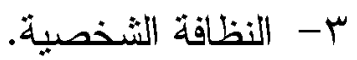

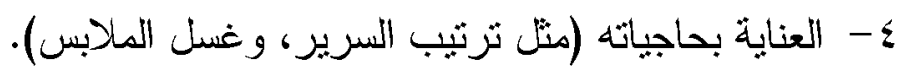
0- مهارات الطهو وإعداد الوجبات.

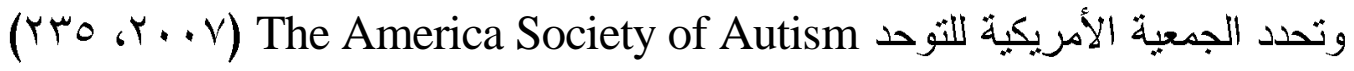
مجالات العناية بالذات على النحو الثالي:

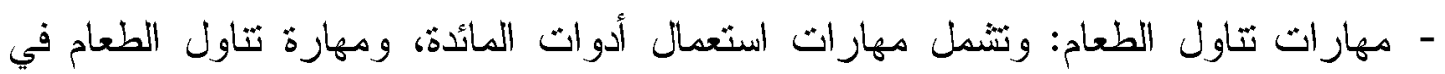
الأماكن العامة، ومهارة نتاول السوائل، ومهارة آداب المائدة. 
- دهارات استعمال المرحاض: ونتشل غسل البدين والوجه، واستخدام المرحاض، وتتظيف الأسنان بالفرشاة، وتمشيط الشعر ، ووضع العطور.

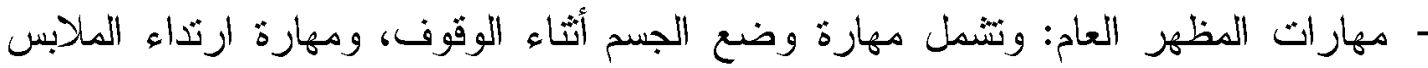
و العناية بها، ومهارة ارتداء الحذاء. - مهارات النظافة: وتشمل مهارة غسل اليدين والوجه، ومهارة الاستحمام، ومهارة الصحة

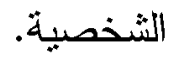
- مهارات النتقل: ونتشمل مهارة استعمال التليفون، ومهارة الخدمات البريدية، ومهارة معرفة المؤسسات العامة.

\section{سابعاً: التدريب على مهارات العناية بالذات:-}

توجد مجموعة من الإرشادات يجب إنباعها عند تدريب الأطفال ذوي اضطر اب طبف

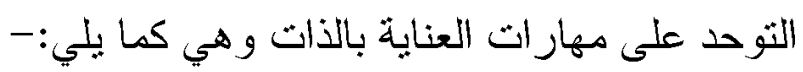

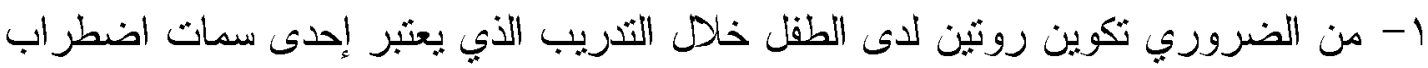
طيف التوحد لذلك ينبغي الاستفادة منه في تدريب الطقل على دهار ات العناية بالذات.

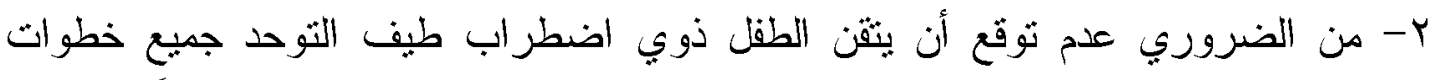
التشريب في وقت واحد، و عدم محاولة تدريبه على جميع مهار ات العناية بالذات معاً.

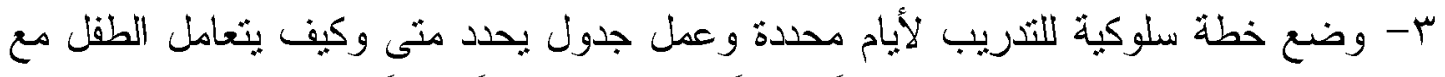

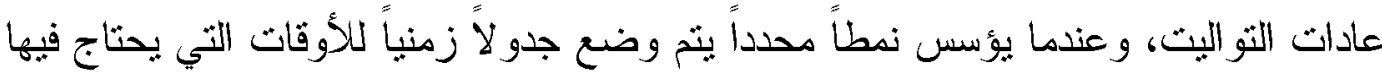
الطقل إلى الذهاب للتو اليت، و اتباع روتين محدد لإجراءات التثريب مشتنملة استعمال المناديل

$$
\text { الورقية و غسل الأبدي. }
$$

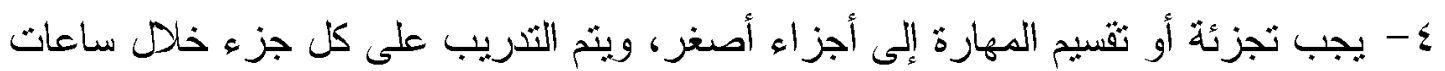

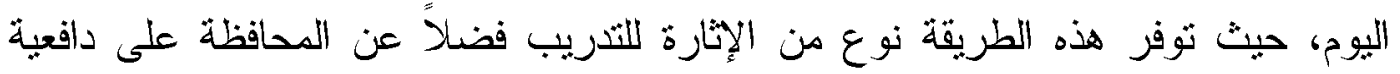
الطفل لإكتساب المهارة. 0- التأكد من عدم وجود مشكلة صحية لدى الطفل تمنعه من التذرب على استخدام المرحاض في القيام بالحمام الخفيف أو التقبل.

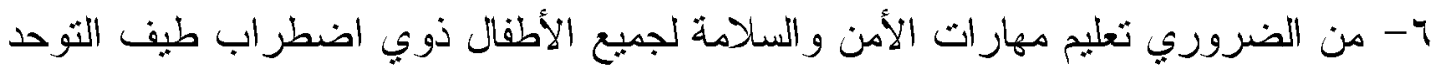

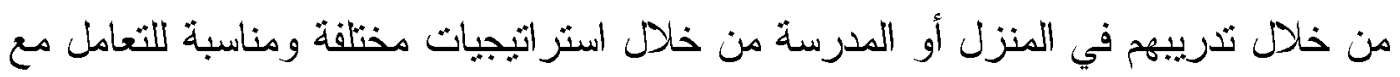
الأخطار، وحماية أنفسهم من الحوادث سو اء في المنزل أو الثنار ع أو المدرسة أو أبي مكان 
بيواجدون فيه، وعلى هذا بثصرفون بأمان في أي موقف خطر، ومن ثم يتجنبون الوقوع في

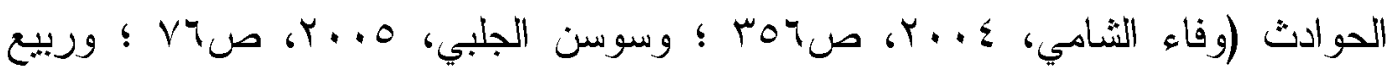

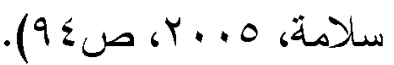

\section{اللثراســـات السابة}

\section{المحور الأول : دراسات تناولت إعداد مقاييس لمهارات العناية بالذات للأطقال ذوي اضطراب طيف}

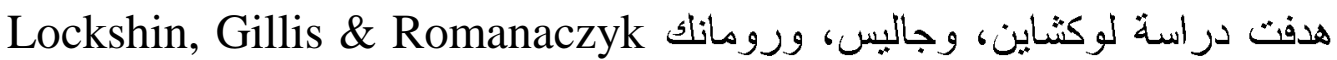

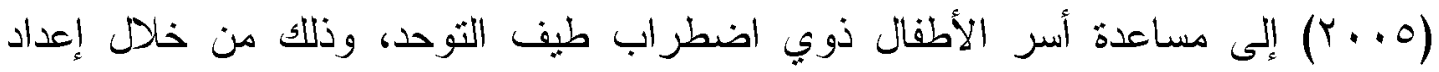
مقياس لمهارات العناية بالذات وتطبيق برنامج تحليل السلوك النطبيقي لتعليم الأطفال ذوي اضطر اب طيف التوحد مهار ات جديدة، ومنها مهارات العنابة بالذات - التو اصل - مهار ات السلو ك الاستثلالي.

\section{وقد توصلت الاراسة إلى النتائج التالية:}

• أن البرنامج المعد له ثأثير كبير في تتمية المهارات المسنهدفة، كما ساعد الآباء على

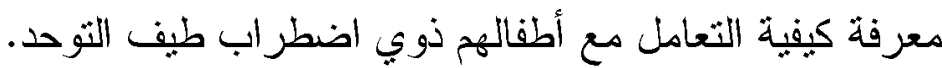
النأكيد على دور الأسرة في تنفيذ بر امج الأطفال ذوي اضطر اب طيف التوحد.

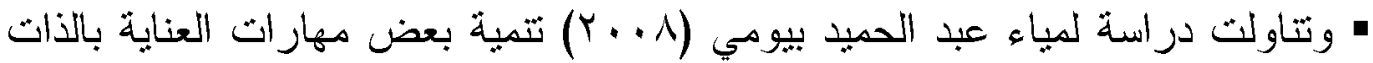
لاى الأطفال ذوي اضطراب طيف التوحد من خلال برنامج تدريبي وقياس فاعليته، وقد نكونت عينة الدراسة من (Y (Y) طفل من أطفال النوحد ثتراوح أعمار هم ما بين (Y-q) سنة. وقد استخدمث الباحثة الأدوات التالية: مقياس المستوى الاجنماعي الاقتصادي للأسرة، ومقياس ستانفورد بينيه للأكاء الصورة الرابعة، و استمارة لمعرفة أنواع المعززات المحبية للطفل التوحدي (إعداد الباحثة)، ومقياس مهارات العناية بالذات للطفل التوحدي (إعداد الباحثة)، وبرنامج ندريبي لنتمية مهارات العناية بالذات

$$
\text { للطفل التوحدي (إعداد الباحثة). }
$$

وقد توصلت الاراسة إلى التتائج التالية: توجد فروق ذات دلالة إحصائية بين مثوسطي الرثب في كل من القياسين القبلي و البعدي لمقياس مهارات العناية بالذات على جميع الأبعاد الفرعية وكذلك دجموع الأبعاد 


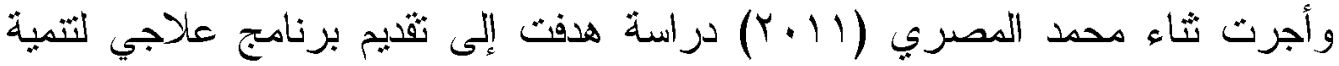

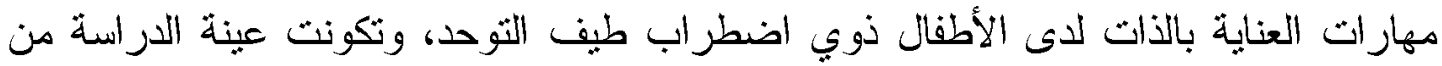

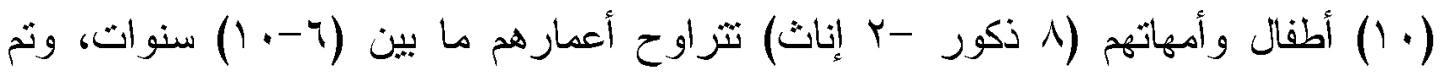

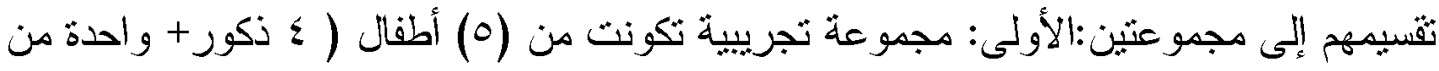

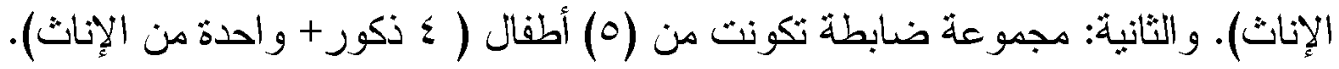

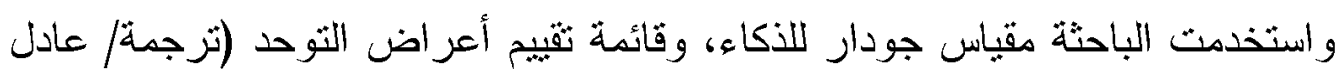

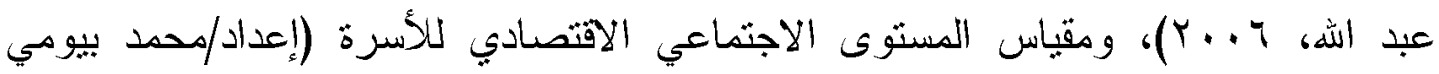

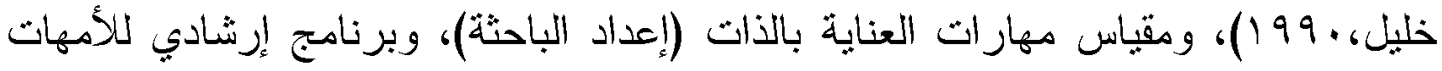
(إعداد الباحثة)، و البرنامج العلاجي التربوي (تيتش) (إعداد الباحثة). وقد توصلت الاراسة إلى النتائج التالية: فعالية البرنامج العلاجي (تيتش) المستخدم في الدراسة في تتمية مهارات العاته العناية بالذات

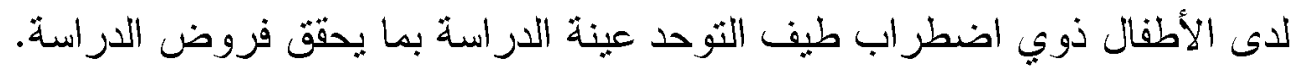

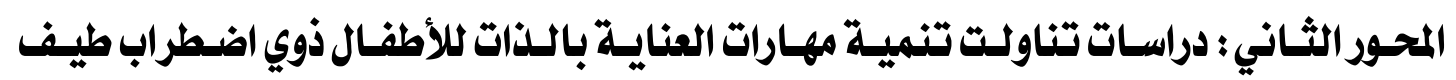

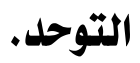

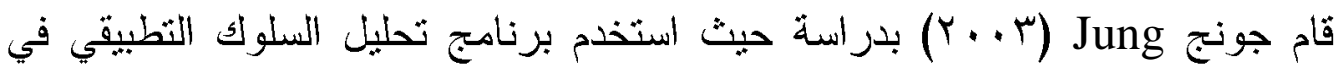
تتمية مهارات العناية بالذات، والمهارات الاجتماعية، والسلوكيات الاجتماعية الإيجايية، ونم

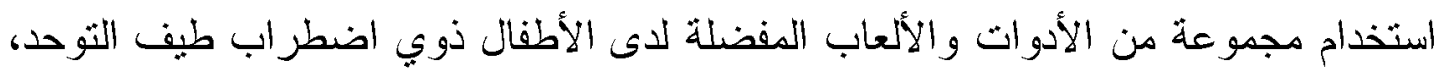

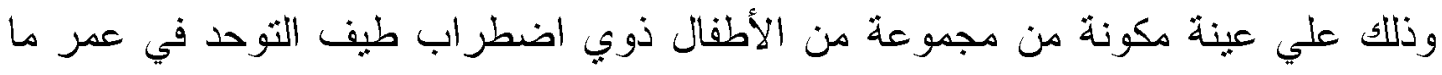
قبل المدرسة.

وتوصلت الاراسة إلى النتائج التالية:

• أن استجابة الأطفال ذوي اضطر ابت طيف التوحد للبرنامج كانت مرتفعة، وأصبحوا

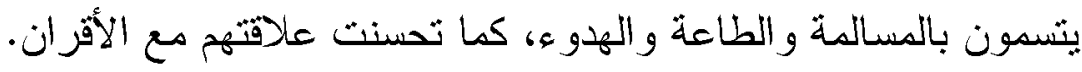

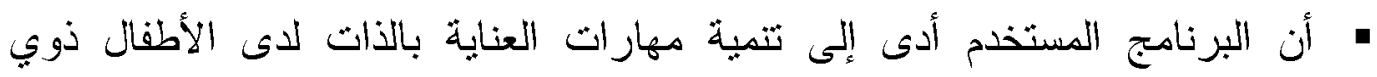

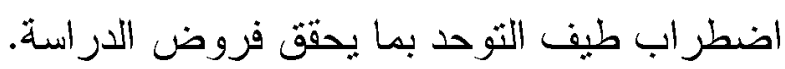

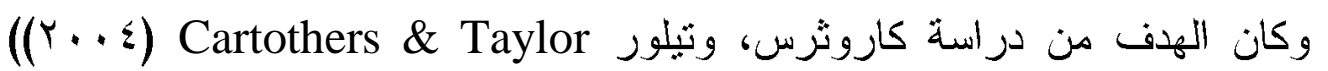

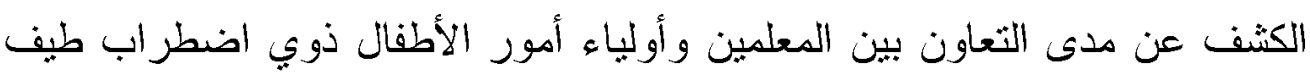

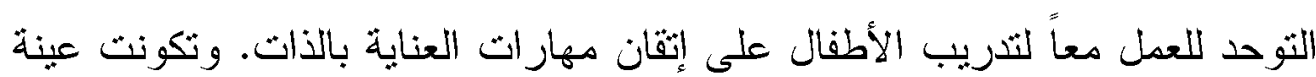




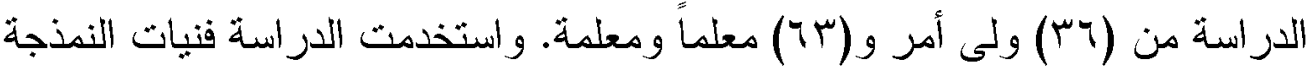
بالفيديو، و الجداول المصورة، وتدريس الأقران. وتوصلت الاراسة إلمى: فعالية التعاون بين المعلمين و الوالدين حيث أدى إلى حدوث ثطور في إكساب مهارات العناية بالذات للأطفال ذوي اضطر اب طيف التوحد.

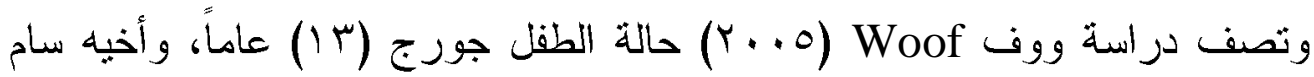
(11) عاما المصابان بإضطر اب طيف التوحد، وتم اللجوء إلى برنامج تحليل السلوك التطبيقي واستخدامه مع الطفلين وتوصلت الاراسة إلى النتائج التالية: أن سام بـام وجورج أصبحا أكثر استجابة وأكثر تتظيماً وأكثر نشاطاً، ولديهم القرة في الاعنماد على أنفسهم في قضاء حاجاتهم.

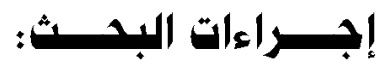

عينة المقياس:

ثم ثقنيين المقياس على عينة مكونة من ثنلثين طفلا من الأطفال ذوي اضطر بـ طبف التوحد من عدد من مراكز تأهيل الأطفال ذوي الاحتياجات الخاصة بمحافظة الثرقية، نتراوح

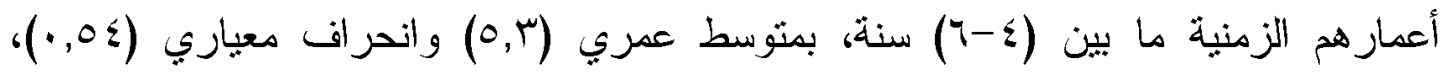
ومعاملات ذكائهم ما بين (-00- V) درجة على مقياس سثانفورد بينه. جلدول (1) وصف العينة المستخلمة في إعداد وتقنين المقياس.

\begin{tabular}{|c|c|c|c|c|c|}
\hline درجة مهارات العناية بالذات & درجة التوحلية & 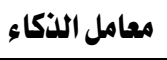 & المعر - المر & 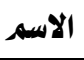 & مر \\
\hline rr & Ar & $\Delta \Lambda$ & 7 & م.س & 1 \\
\hline PV & 10 & 70 & $0, Y$ & $i . \varepsilon$ & $r$ \\
\hline ro & Ar & $7 \xi$ & 0,1 & م.ع & $r$ \\
\hline rr & $\Lambda^{\circ}$ & 70 & $\boldsymbol{\xi}, 0$ & $\Delta . \varepsilon$ & $\varepsilon$ \\
\hline$r q$ & A. & 71 & 0,0 & م. هـ & 0 \\
\hline$r A$ & A. & v. & 0 & أ. & 7 \\
\hline
\end{tabular}

قام الباحث ببناء مقياس لثقدير مهارات العناية بالذات لدى الأطفال ذوي اضطراب طيف التوحد، وقد تم التحقق من الصدق باستخدام صدق المحكمين، كما تم التحقق من الثبات باستخدام طريقة إعادة النطبيق. 


\section{خطوات بناء المقياس: - اس}

أمكن للباحث صياغة مفردات المقياس من خلال بعض المصادر منها:

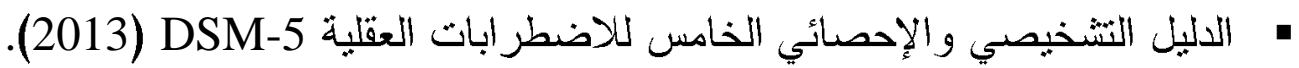

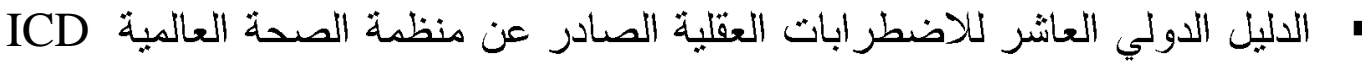
.(1993) -10

ومن خلال الإطار النظري و الدراسات السابقة التي أطلع عليها الباحث.

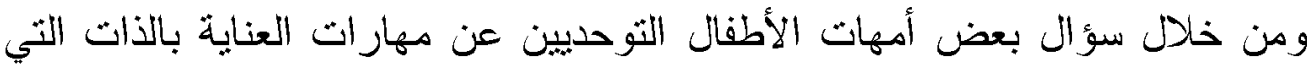

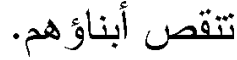

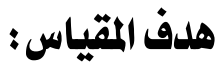
يهدف المقياس إلى نقدير درجة إتقان مهار ات العناية بالــذات لــدى الأطفــال ذوبي اضطراب طيف التوحد الذين تنز اوح أعمار هم ما بين (ع-؟) سنوات.

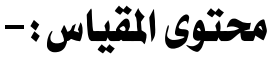
يتكون المقياس من (·r) مفردة موزعة على أربعة أبعاد أساسية وهي: • البعد الأول: مهارات نتاول الطعام و الثراب ويحتوى على م مفردات وتثضنمن: (تتاول

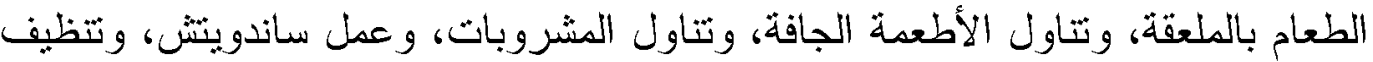

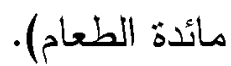

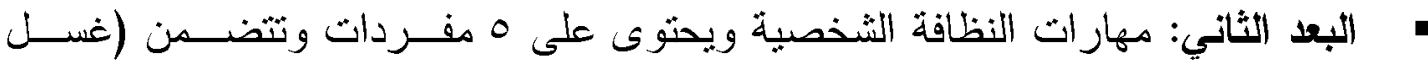

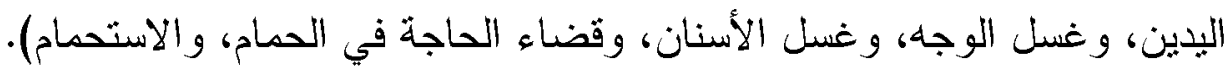

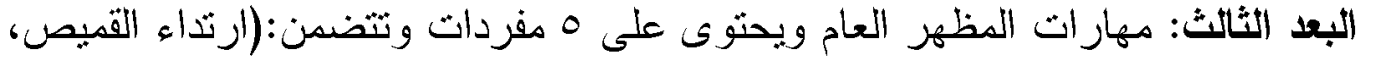
وارتداء البنطلون، وارتداء الثراب، وارتداء الحذاء، وخلع الملابس).

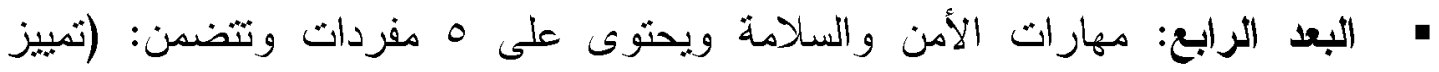

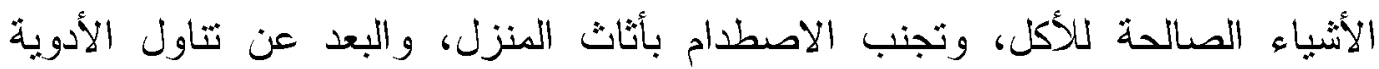

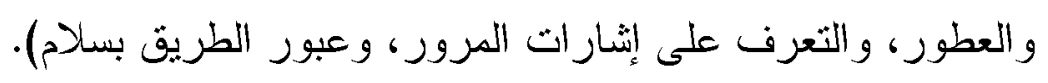

الخصائص السيكومترية لمقياس:

صدق المهكمين:

قام الباحث بالتحقق من صدق المقياس عن طريق صدق المحكمين وذلك بعرضه

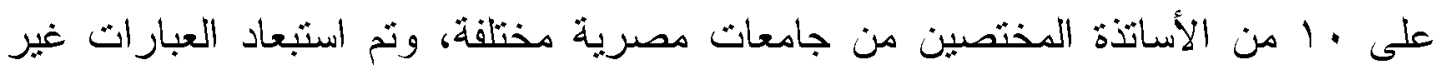
المتفق عليها بنسبة أكبر من •^ر\% وكذلك الأخذ بمقترحات السادة المحكمين. 
جلدول (r ) نسب اتفاق السادة المحكمين على مقياس تقلير مهارات العناية بالذات.

\begin{tabular}{|c|c|c|c|c|}
\hline \multirow{2}{*}{ الاتفاق } & \multicolumn{2}{|c|}{ عدد المحكمين } & \multirow{2}{*}{ اسم الفقزة } & \multirow{2}{*}{ رقم الفقرة } \\
\hline & غير مناسبة & مناسبة & & \\
\hline & & & مهارات تناول الطعام والثراب & $\bullet$ \\
\hline$\% 1 \ldots$ & - & 1. & يتتاول الطفل الطعام باستخدام ملعقة. & 1 \\
\hline$\% 1 \ldots$ & - & 1. & يتتاول الطفل الأطعمة الجافة باستخدام أصدابعه. & r \\
\hline$\% 1 \ldots$ & - & 1. & يشرب الطفل الماء في كوب باستقلالية. & r \\
\hline$\% 9$. & 1 & 9 & يستطيع الطفل أن يعمل ساندويتش لنفسه. & $\varepsilon$ \\
\hline \multirow[t]{2}{*}{$\% 1 \ldots$} & - & 1. & يساعد الطفل في تنظيف مائدة الطعام. & 0 \\
\hline & & & مهارات النظافة الثخصية & $\bullet$ \\
\hline$\% 1 \ldots$ & - & 1. & يغسل الطفل يديه قبل الأكل وبعـده. & 1 \\
\hline$\% 1 \ldots$ & - & 1. & يغسل الطفل وجهه بالماء و الصدابون. & r \\
\hline$\% 1 \ldots$ & - & 1. & يغسل الطفل أسنانه بالفرشاة و المعجون. & r \\
\hline$\% 9$. & 1 & 9 & يستخدم الطفل الحمام في قضداء الحاجة. & $\varepsilon$ \\
\hline \multirow[t]{2}{*}{$\% 1 \ldots$} & - & 1. & يستطيع الطفل الاستحمام بشكل مناسب. & 0 \\
\hline & & & مهارات المظهر العـام & $\bullet$ \\
\hline$\% 1 \ldots$ & - & 1. & يرتدي الطفل القميص باستقلالية. & 1 \\
\hline$\% 1 \ldots$ & - & 1. & يرتدي الطفل البنطلون باسنثلانية. & r \\
\hline$\% 1 \ldots$ & - & 1. & يرتدي الطفل الثشراب باستقللية & $r$ \\
\hline$\% 1 \ldots$ & - & 1. & يرتدي الطفل الحـــذاء باستقلالنية. & $\varepsilon$ \\
\hline \multirow[t]{2}{*}{$\% 9}$. & 1 & 9 & يخلع الطفل الملابس الذاصة بـه. & 0 \\
\hline & & & مهارات الأمــن والسلامة & $\bullet$ \\
\hline$\% 1 \ldots$ & - & 1. & يميـزز الطفل الأشياء الصـالحة للأكل. & 1 \\
\hline$\% 1 \ldots$ & - & 1. & يتجنب الطفل الاصطدام بأثاث المنزل. & r \\
\hline$\% q$ & - & 9 & يبتعد الطفل عن تتاول الأدوية أو العطور. & $r$ \\
\hline$\% 1 \ldots$ & - & 1. & يتعرن الطفل على إثار ات المرور. & $\varepsilon$ \\
\hline$\% \wedge$ & r & $\lambda$ & يستطيع الطفل عبور الطريق بسلام. & 0 \\
\hline
\end{tabular}


تم حساب الثبات بطريقة إعادة النطبيق عن طريق استخدام مصفوفة ارتباط بيرسون بين النطبيقين الأول والثاني بفاصل خمسة عشر يوماً. وفيما يلي معاملات الارتباط بين

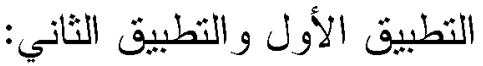

\begin{tabular}{|c|c|c|}
\hline الارنباط & البعــد & 5 \\
\hline$* *, 90 \lambda$ & مهارات تتاول الطعام والثراب & 1 \\
\hline שr * & مهارات النظافة الثخصبة & r \\
\hline$* *, \wedge 9 \leq$ & مهارات المظهر العام & r \\
\hline$* * ., 9 \mu \lambda$ & مهار ات الأمن والسلامة & $\varepsilon$ \\
\hline
\end{tabular}

وقد أسفرت نتائج المصفوفة عن انساق بيانات المقياس في مرني النطبيق لدلالة

$$
\text { جميع عو امله. }
$$

كما تم تقدير دصفوفة الارتباطات بين درجات الأبعاد الأربعة باستخدام معامل ارتباط

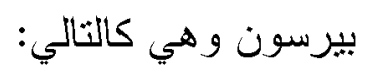

\begin{tabular}{|c|c|c|c|c|}
\hline (4) & $(\mu)$ & $(Y)$ & (1) & الأبعاد \\
\hline & & & 1 & (1) مهارات تتاول الطعام \\
\hline & & 1 & $(* *) \cdot 9 Y 1$ & (Y) مهار ات النظافة \\
\hline & 1 & $(* *) \cdot, 949$ & $(* *) \cdot, 9 Y \lambda$ & (T) مهار ات المظهز العام \\
\hline 1 & $(* *) \cdot, 9 \times q$ & $\left(^{* *}\right) \cdot, 9 Y \lambda$ & $(* *) \cdot, \vee \vee \wedge Y$ & (乏) مهار ات الأمن \\
\hline
\end{tabular}

جلدول (§) معاملات مصفوفة الارتباطات لأبعاد مقياس تقدير مهارات العناية بالذات.

وقد أسفرت نتائج المصفوفة عن مصداقية المقياس نظراً للارتباط بين الأبعاد

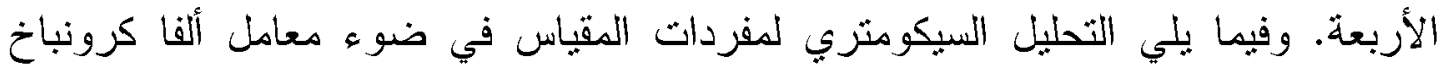

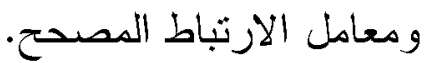




\section{جلدول (0) ثبات المفردات ومعامل الارتباط المصحج لأبعاد المقياس.}

\begin{tabular}{|c|c|c|c|c|}
\hline ثنبات & معامل الارثباط & الثبات عند حذف & المفردة & البحــد \\
\hline \multirow{5}{*}{$\cdot, Y \wedge \varepsilon$} & $\cdot, \Sigma Y \Sigma$ & $\cdot, T \leqslant V$ & 1 & \multirow{5}{*}{ مهار ات ثتاول الطعام } \\
\hline &., 779 &.,$O Y V$ & r & \\
\hline & $\cdot, \mu q v$ &., $70 \leqslant$ & r & \\
\hline & דצ' & $\cdot T \wedge r$ & $\varepsilon$ & \\
\hline & י, & $\cdot, 7 \leq$. & 0 & \\
\hline \multirow{5}{*}{$\cdot, \vee \vee 0$} & $\cdot, \Sigma \mu \wedge$ & $\because, Y Y$. & 1 & \multirow{5}{*}{ مهار الث النظافة } \\
\hline & $\cdot, r \vee \varepsilon$ & $\cdot, T \leqslant V$ & r & \\
\hline & דצחד, & $\cdot, V \backslash V$ & $r$ & \\
\hline & $\cdot, \Sigma Y r$ & דצדי & $\varepsilon$ & \\
\hline & •,rqM & $\because, \vee \wedge T$ & 0 & \\
\hline \multirow{5}{*}{$\cdot, V \cdot Y$} & $\therefore, \Sigma Y 0$ & $\cdot, 797$ & 1 & \multirow{5}{*}{ مهار ات المظهر العام } \\
\hline & $\cdot, O V Y$ & $\cdot V \cdot V$ & r & \\
\hline & • MVo &., 797 & $r$ & \\
\hline & $\cdot, 0 \leq \lambda$ & $\cdot, 71 \mathrm{~V}$ & $\Sigma$ & \\
\hline & $\cdot, \varepsilon \cdot r$ & $\cdot, T \vee T$ & 0 & \\
\hline \multirow{5}{*}{$\cdot, \vee \vee \wedge$} &., 019 & $\cdot, \vee \vee \wedge$ & 1 & \multirow{5}{*}{ مهار ات الأمن } \\
\hline & $\cdot, T 1 Y$ & $\cdot, v \leq 9$ & r & \\
\hline & $\cdot, 7 \wedge 1$ & $\cdot, V Y V$ & $r$ & \\
\hline &., 017 & $\because, \vee \wedge O$ & $\varepsilon$ & \\
\hline &., 091 & $\cdot$, VOT & 0 & \\
\hline
\end{tabular}

تصصبح المقباسر:-

يتكون المقياس هن · r مفردة وله ثثلثة اختيارات مكونة هن (بستطيع بمفردة يسنطيع بمساعدة - لا يسنطيع)، وكان المقباس مفرداته كلها إيجابية وكانت درجة تصحيحه

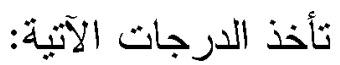
يستطبع بمفرده = وبالثالي فإن أعلى درجة يمكن أن يحصل عليها الطفل (·ت) درجة، وأقل درجة

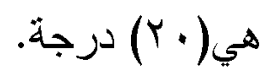




\section{طريقة تطبيز المقياسر:-}

تطبيق المقباس فردياً على (الأمهات - معلمو النربية الخاصة) للأطفال ذوبي

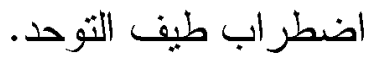

\section{نتائج البحث والمقترحات المرتبطة بها:}

1- أن مهارات العناية بالذات هي مجموعة من القدرات والأنشطة التي نساعد الطفل على

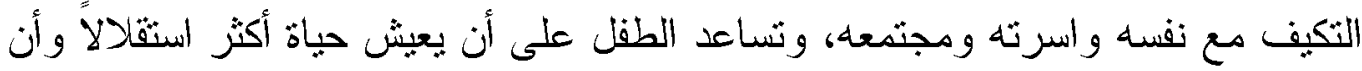
يحسن التصرث في حالات الطوارئ والأنشطة اليومية المختلفة. ولذلك يوصي الباحث بضرورة التدريب على مهارات العناية بالذات منذ مرحلة الطفولة المبكرة في عمر الطفل ذو اضطراب طبف التوحد؛ لأنها نساعده داخل

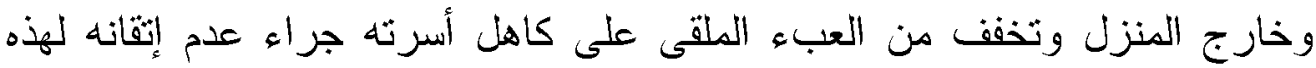

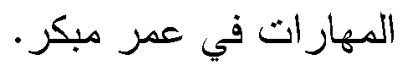

r- أن مهارات العناية بالذات تثيكل أساساً لبناء أثنكال أخرى من المهارات اللاحقة كالمهارات الأكاديمية أو الاجنماعية أو المهنية، وأن أداء الطقل للمهارات الاستقلالية يؤدي إلى تنمية

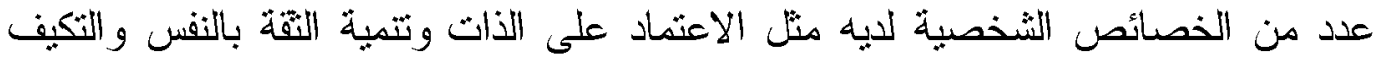

$$
\text { الناجح مع من حوله. }
$$

ولذلك بوصي الباحث بضرورة التعاون التام بين الأسرة ومراكز التأهيل المختلفة في التسيق ووضع خطة تأهيل وتدريب الطفل ذو اضطر اب طيف التوحد على مهارات

$$
\text { العناية بالذات وباقي المهارات الاستقلالية الأخرى. }
$$

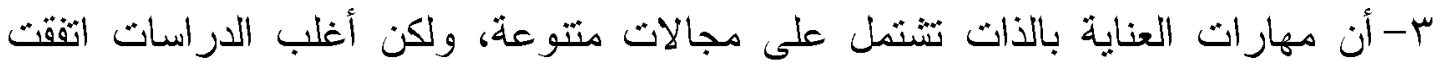
على وجود أربعة مجالات رئيسية لها وهي: مهارات تتاول الطعام والثشراب، ومهارات النظافة الثخصية، وهمارات المظهر العام، ومهارات الأمن و السلامة.

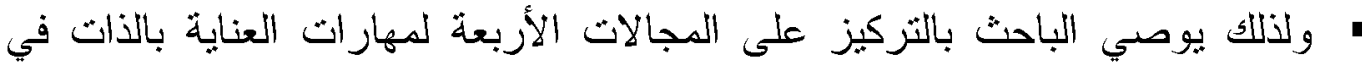

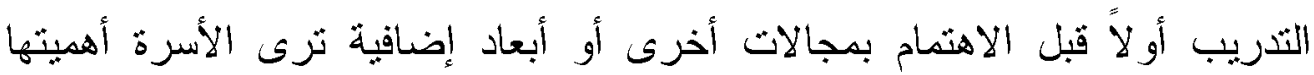




\section{المراجـــ}

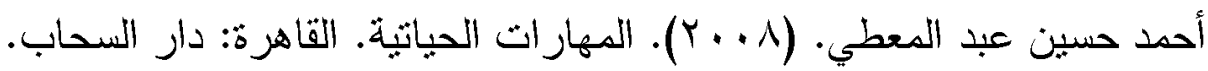

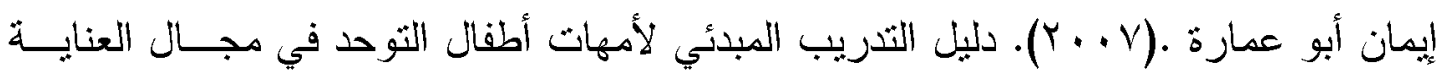

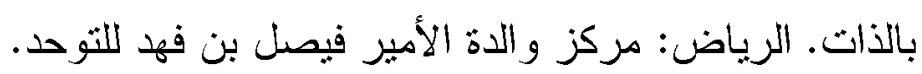

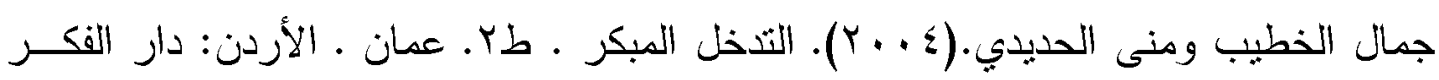
للنشر و الثوزيع.

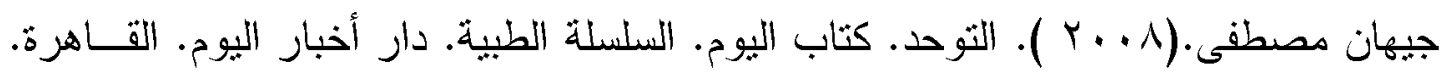

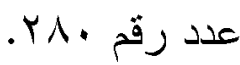

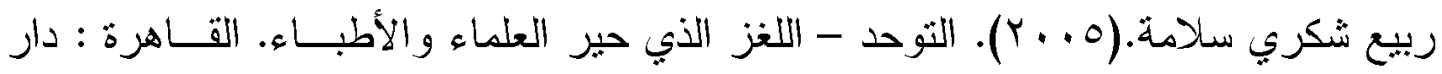

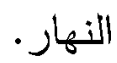

سوسن شاكر الجلبي.(0 . ب). النوحد الطفولي "أسبابه - خصائصده - تشخيصده - علاجه".

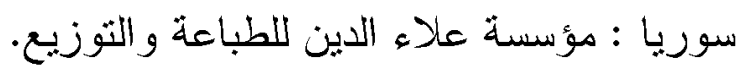

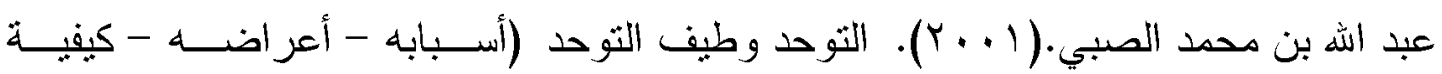

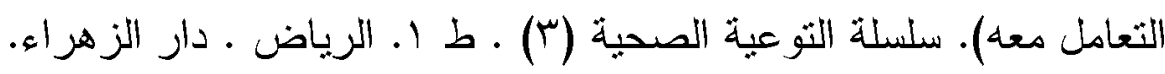

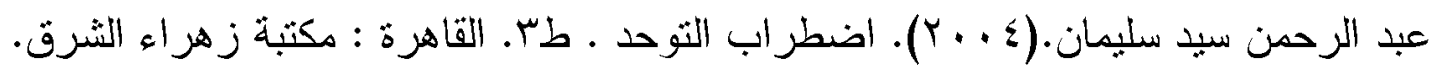

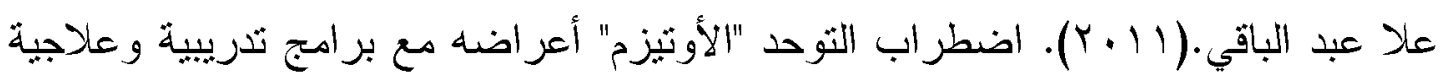

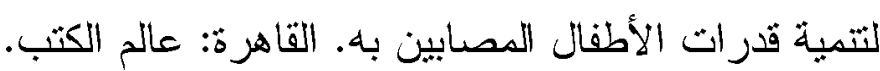

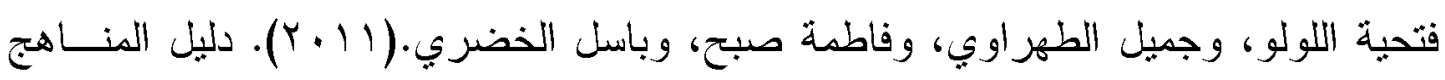

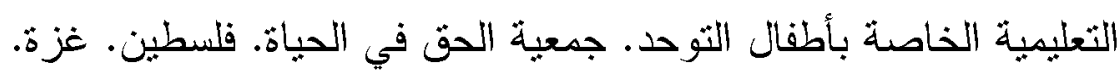

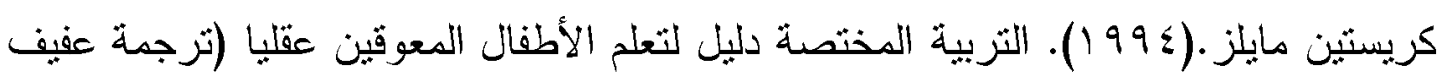

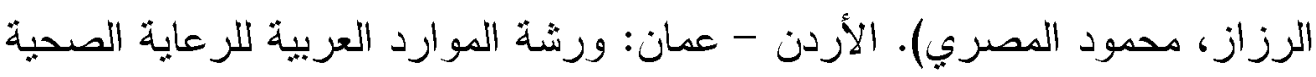

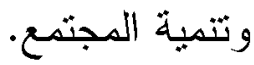

كمال سالم سيسالم.(Y . . Y). موسوعة التربية الخاصة و التأهل النفسي. العين: دار الكتــاب الجامعي.

محد السيد عبد الرحمن ومنى خليفة على حسن.(0. . ؟). رعاية الأطفال الثوحدين. دليل

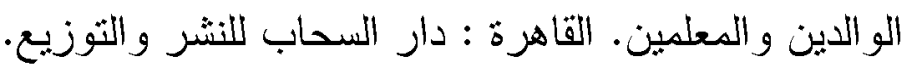


Belfiore, P., \& Mace, C. (1994): Self- help and community skills, In: Johnny K. Matson (Ed) Autism in children and adults. Etiology, assessment, and intervention. Pacific Grove, California: publishing company.

Boswell, S., Susan, G., \& Debbie, F. (2003). Applying structured teaching principles to toilet training, U.S. North California. Journal Announcement: RIE, Oct.1999.

Brill, M. (1994). Keys to parenting the child with autism, New York: Baron's Educational Series, Inc

James, A. G., Tekin-Iftar, E.M., \& Kircaali-Iftar, G.D. (2009). Effects of antecedent prompt and Test Procedure on Teaching simulated menstrual care skills to females with Developmental Disabilities. Education and Training in Developmental Disabilities, 44, 54-66.

Jung, S.M. (2003) .Using high- probability request sequences to increase social interaction in young children with autism. Dissertation Abstracts International, 65, 406- 4015.

Kanner, L. (1943). Autistic disturbances of affective contact, The Nervous Child, 34 50- 217.

Lockshin, S.M., Gillis, T.M., \& Romanaczyk, R.G. (2005). Helping your child with autism: A step - by - step workbook for families. Oakland, CA, US: New Harbinger Publications, 45, 227-231.

Michigan Department of Community Health. (2006). Promising Practices in Wraparound for Children with Serious Emotional Disturbances and their Families. Journal of Applied Behavior Analysis, 6, 85-100.

World Health organization. (1993). ICD -10 international statistical classifications of Diseases and Related health problems. 10th review. Geneva: Division of Mental Health Publications. 


$$
\text { هذه المقباس موجه إلى (الأب - الأم - المعلمة). }
$$

هذا المقياس بيتخدم لأغر اض البحث العلمي فقط ولن يستخدم في غير ذلك.

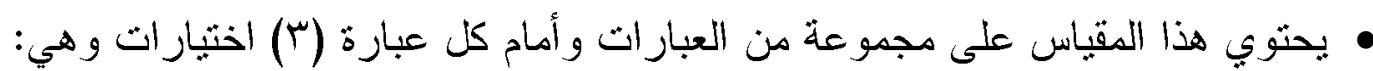

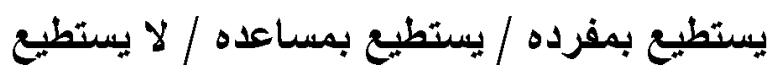

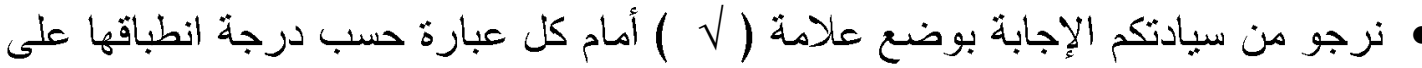

$$
\text { الطقل. }
$$

• لا توجد إجابة صحبحة وأخرى خاطئة، و إنما هي سلوكيات تثو افر في الطقل أو لا.

$$
\text { • • ن نرجو عدم نرك أبي عبارة بدون إجابة. }
$$

وشكرا لحسن

$$
\text { تعاونكم }
$$

الباحث 


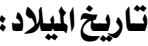

الســنـ:

\begin{tabular}{|c|c|c|c|c|}
\hline 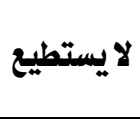 & بمساعليع & بمفردهيع & الـعـبــــارات & هـ \\
\hline & & & يتناول الطفل الطعام باستخدام ملعقة. & 1 \\
\hline & & & يغسل الطفل يليه قبل الاكل وبعلده. & r \\
\hline & & & يرتدي الطفل القميص باستقلالية. & r \\
\hline & & & يميز الطفل الأشياء الصالحة للأكل دون غيرها. & $\xi$ \\
\hline & & & يتناول الطفل الأطعمة الجافة باستخداه أصابعه. & 0 \\
\hline & & & يغسل الطفل وجهه بالماء والصابون. & 7 \\
\hline & & & يرتدي الطفل البنطلون باستقلالية. & $\checkmark$ \\
\hline & & & يتجنب الطفل الاصطدام بأثاث المنزل مثل الأبواب. & $\wedge$ \\
\hline & & & يشرب الطفل الماء في كوب باستقلالية. & 9 \\
\hline & & & يغسل الطفل أسنانه بالفرشاة والمعجون. & 1. \\
\hline & & & يرتدي الطفل الشراب باستقلالية & 11 \\
\hline & & & يبتعل الطفل عن تناول الأدوية أو العطور. & ir \\
\hline & & & يستطيع الطفل أن يعمل ساندويتش لنفسه. & ir \\
\hline & & & يستخلدم الطفل الحمام في قضاء الحاجة. & iq \\
\hline & & & يرتدي الطفل الحذاء باستقلالية. & 10 \\
\hline & & & يتعرف الطفل على إشارات المرور. & 17 \\
\hline & & & يساعل الطفل في تنظيف مائدة الطعام. & iv \\
\hline & & & يستطيح الطفل الاستحمار بشكل مناسب. & in \\
\hline & & & يخلع الطفل بعض ملابسه باستقلالية. & 19 \\
\hline & & & يستطيع الطفل عبور الطريق بسلاه. & r. \\
\hline
\end{tabular}

مثال: بتتاول الطفل الطعام باستخدام ملعقة.

\begin{tabular}{|c|c|c|}
\hline ل يستطيح & بستطيع بمساعدة & يستطبح بمفرده \\
\hline & & \\
\hline
\end{tabular}

ضع علامة (ل) في المربع الذب يحدد انطباق العبارة على الطفل. 